\title{
Philologica Canariensia
}

Revista de Filología de la Universidad de las Palmas de Gran Canaria

20 (2014), eISSN: 2386-8635

DOI: en trámite

Andreen GHeorghiu, Compte-rendu. Dialogues francophones, N¹6/2010 : Les francophonies au féminin, Timisoara, Eurostampa, 2010, 486 p. ISSN: 12247073 .

La revue Dialogues francophones se concentre sur la littérature francophone contemporaine et elle est publiée par le Centre d'Études Fran-cophones de la Chaire de Langues romanes de l'université Ouest de Timisoara (Roumanie). Son objectif est de relever les relations qu'entretient la littérature francophone avec les théories littéraires et la littérature comparée, afin d'associer les savoirs au sein d'une réflexion commune. La revue se compose des plusieurs sections: des articles originaux accompagnés de résumés en anglais et en français, des synthèses, des entrevues et des comptes-rendus.

Le numéro 16 de la revue, intitulé «Les francophonies au féminin», est consacré à la contribution des femmes dans l'espace littéraire et scientifique sans frontière de la francophonie contemporaine.

L'introduction, signée par Lucienne J. Serrano, présente l'écriture des femmes dans la littérature francophone contemporaine, écriture qui se fait «révolte intime» en quête d'une parole libérée, déliée de la logique nécessaire au sens original et qui peut atteindre un sens transgressif.
Dans la première section sont soumis à l'analyse les ouvrages de trois écrivaines francophones d'origine roumaine: Fin de chasse, roman publié en 2001 par Rodica Iulian, Alexandra des amours, un roman publié en 2005 par Oana Orlea, et Au bal avec Marcel Proust, un essai-hommage de Marthe Bibesco qui retrace les fondations d'une œuvre évidemment moderne.

Autobiographie, post-féminisme, enjeux de l'écriture féminine et avatars de la féminité sont quelques-uns des aspects étudiés dans les articles du volet «Littératures francophones d'Europe», qui aborde des œuvres des écrivaines belges Dominique Rolin et Claire Lejeune, de l'auteure suisse Catherine Colomb, et des françaises Sylvie Germain et Jeanne Hyvrard.

La section consacrée à l'Afrique Noire rend compte de l'extraordinaire richesse de la littérature féminine du Sénégal (Mariama Bâ, Fatou Diome, Ken Bugul [Mariètou Mbaye Biléoma]), de la Côte d'Ivoire (Fatou Keïta, Flore Hazoumé) et du Cameroun (Werewere Liking, Calixthe Beyala, Lydie Dooh-Bunya, Thérèse 
Kuoh-Moukoury, Léonora Miano) et offre des pistes de réflexion sur l'identité féminine africaine : « négrattitude » féminine et postmodernité, écriture du silence et du corps féminin, écriture transculturelle, stratégies narratives et affirmation de soi.

Réservé au Magreb, le quatrième volet des Dialogues francophones interroge les écrits d'Assia Djebar afin de saisir la conjonction scripturale -picturale dans la génération du texte et les ouvrages de Leila Sebbar- pour montrer que l'exil est un élément porteur de l'entreprise créatrice.

La section concernant la littérature canadienne met en évidence les modalités de constitution du féminin, le déterminisme du signifiant et les liens qui se tissent entre témoignage, créativité et fiction, dans les œuvres d'Anne Hébert, Catherine Mavrikakis, Marie-Célie Agnant et Marie Sissi Labrèche.

La littérature francophone des Caraibes est illustrée dans la sixième section par un fabulo-drame de Suzanne Dracius et les romans policiers de Marie-Reine De Jaham et Michèle Robin-Clerc.

La section des Synthèses propose une lecture comparative de trois romans -de Marie Darrieussecq, Marie Ndiaye et Amélie Nothombqui ont en commun la question des frontières identitaires. L'étude finale, basée sur un vaste corpus d'œuvres francophones contemporaines, met en évidence des traits récurrents (rapport problématique à la langue française, (auto)réflexivité, polyphonie, subversion) et s'interroge sur la possibilité de prendre le roman féminin pour un genre. En fin de compte, si le roman féminin se distingue par une certaine manière de sentir et de re-créer la vie, les choix thématiques et stylistiques privilégiés n'excluent pas la probabilité qu'un écrivain masculin puisse être en mesure d'écrire un roman féminin.

La section finale inclut des entretiens avec deux écrivaines canadiennes-françaises contemporaines, Catherine Mavrikakis, auteur de quatre romans dont le plus récent Le Ciel de Bay City, et Angela Cozea, auteur du roman Interruptions définitives, qui partagent leurs opinons et leurs point de vue sur leurs romans et sur la définition de la spécificité féminine.

Le numéro «Les francophonies au féminin » est une révélation de la manière dont le contexte des littératures francophones s'est avéré apte à faire émerger une double solidarité, féminine et francophone à la fois. Au-delà des frontières, il y a des murmures qui se répondent de la 
France à la Guadeloupe, du Cameroun moderne au Québec contemporain, de la Roumanie au Maghreb, pour parler de l'exil hors langue et hors pays, pour revendiquer plus d'autonomie et de liberté, pour exprimer la douleur et la révolte des femmes, pour souligner finalement le rapport entre soi et l'autre ou de « soi-même comme un autre ».
La variété complexe de ce numéro de la revue Dialogues francophones le rend unique parmi les études entreprises dans le domaine en s'adressant aux professeurs, aux chercheurs et aux étudiants qui s'intéressent aux études féminines et à la littérature francophone contemporaine.

Carlo Lavoie

Université de l'Île-du-Prince-Édouard 
